\title{
Inundações urbanas e as técnicas de redução de escoamento superficial de águas pluviais
}

\author{
Urban floods and the techniques of reducing water surface flow \\ Neto, J.A.F ${ }^{1}$; Oliveira H.C.de ${ }^{2}$; Oliveira, N.K.de ${ }^{3}$; Cunha A.da.S ${ }^{4}$ \\ 1,2,3,4 Universidade do Estado de Minas Gerais, João Monlevade, MG, Brasil. \\ jose.neto@uemg.br
}

\begin{abstract}
RESUMO
O objetivo deste trabalho é discutir as causas das atuais inundações urbanas brasileiras e apresentar meios e técnicas disponíveis para minimizar ou findar esses eventos, considerando que o crescimento da população urbana brasileira nas últimas décadas gerou problemas relacionados ao escoamento superficial de águas pluviais nas cidades. As altas taxas de impermeabilização do solo acarretam perda da capacidade de infiltração da água pluvial culminando em inundações urbanas, com isso viu-se a necessidade de criação e implantação de novas tecnologias que podem diminuir ou cessar tais problemas. Técnicas de pavimentação com materiais que permitem maior infiltração de águas pluviais representam métodos de redução do escoamento superficial e aumento da permeabilidade do solo. Este artigo foi realizado com base em referenciais bibliográficos que tratam de assuntos relacionados à drenagem urbana, escoamento superficial e tipos de pavimentos.
\end{abstract}

Palavras-chaves: Escoamento superficial, Impermeabilização, Pavimentação.

\begin{abstract}
The purpose of this paper is to discuss the causes of the current Brazilian urban flooding and to present available means and techniques to minimize or end these events. Since, with the increase of the average urban population in the last decades, great problems have arisen related to the surface runoff of rainwater in the cities. High soil sealing rates can reduce rainfall infiltration capacity leading to urban floods, with this was the need to create and deploy new technologies that would reduce or stop such problems. This article was based on bibliographical references that deal with issues related to urban drainage, surface runoff and types of pavements. As the method of reducing runoff and increasing soil permeability, paving techniques are used with materials that allow greater infiltration of rainwater.
\end{abstract}

Keywords: Surface runoff, Waterproofing, Paving. 


\section{INTRODUÇÃO}

Diante da urbanização descontrolada associada à falta de planejamento das grandes cidades brasileiras, houve um aumento considerável de enchentes urbanas que são decorrentes, principalmente, da impermeabilização dos solos. Segundo Tucci (1995), o processo de urbanização acelerada ocorreu no Brasil depois da década de 1960, gerando uma população urbana com sérios problemas, dentre eles as inundações urbanas.

O desenvolvimento urbano altera a cobertura vegetal provocando vários efeitos que alteram os componentes do ciclo hidrológico natural (TUCCI, 1995). Essas alterações ocorrem devido à impermeabilização dos solos. Com isso, há diminuição da infiltração da água que, por consequência, escoa superficialmente, causando danos à população devido às enchentes de maior magnitude.

Para a atenuação dessas alterações, um mecanismo utilizado para promover a infiltração da água precipitada no solo urbano é o pavimento permeável. Para Alessi et. al. (2006), a tendência atual na área de drenagem é buscar novas tecnologias que tendam a aumentar o índice de infiltração e a reduzir o escoamento superficial. Um caminho para esse tipo de abordagem é o estudo do uso de pavimentos permeáveis por serem capazes de reduzir o volume do escoamento em comparação aos pavimentos convencionais.

Esse tipo de pavimento busca diminuir o volume de água que escoa superficialmente e, por consequência, reduzir a solicitação do sistema de drenagem urbana e as enchentes. Exemplo disso é o asfalto permeável que, devido a sua estrutura porosa, é reconhecido como um grande aliado para a solução de problemas enfrentados por diversas cidades.

\section{MATERIAIS E MÉTODOS}

A fundamentação teórica e conceitual do trabalho em questão foi baseada em trabalhos de referência sobre a tecnologia aplicada aos pavimentos, especificamente, ligada à questão da permeabilidade desses diante dos problemas de escoamento pluvial em área urbana. $\mathrm{O}$ estudo do material bibliográfico sobre pavimentos permeáveis se baseou, principalmente, em artigos atinentes ao tema, bem como em livros e revistas que tratam a problematização do escoamento pluvial em áreas urbanas e soluções técnicas 
que garantem a permeabilidade da água no solo, garantindo a recarga do lençol de água subterrâneo.

\section{REVISÃO BIBLIOGRÁFICA}

\subsection{Histórico dos processos de impermeabilização}

O crescimento da população brasileira nas últimas décadas foi de grande percentual e, na última década, a população urbana ultrapassou $83 \%$, conforme o gráfico 1 abaixo. O processo de urbanização acelerado ocorreu depois da década de 1960, gerando uma população urbana sem infraestrutura, principalmente, na década de 1980, quando os investimentos foram reduzidos (TUCCI, 1995). Esse crescimento ocorreu devido ao aumento da industrialização, contribuindo, assim, para o êxodo rural.

Gráfico 1 - Evolução da urbanização no Brasil

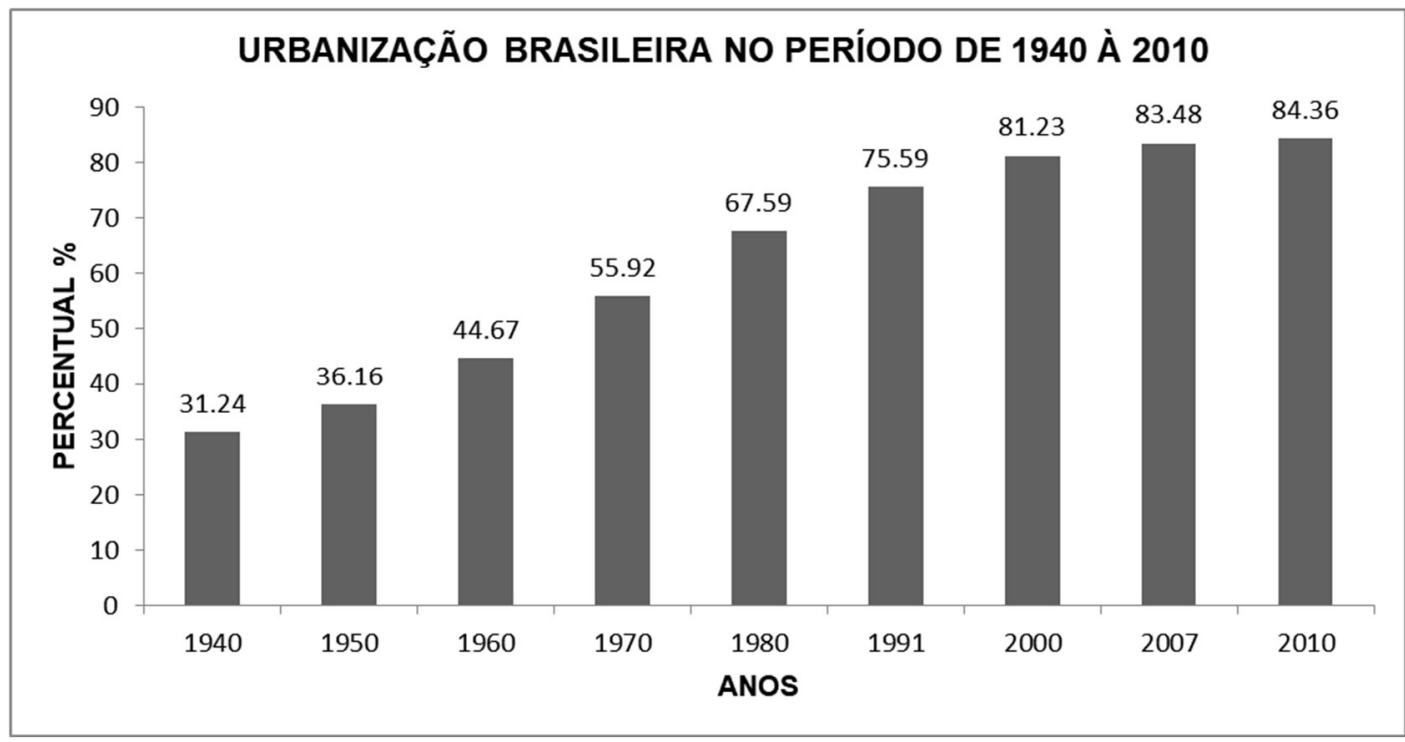

Fonte: IBGE, 2007.

Segundo Tucci (2008), a urbanização pode ser espontânea, considerando que muitas áreas ilegais e públicas são ocupadas indevidamente, sem qualquer tipo de planejamento. $\mathrm{O}$ desenvolvimento rápido e mal planejado das cidades contribuiu para a evolução dos problemas de impermeabilização do solo e, de acordo com Teixeira et al. (2003), as construções e a pavimentação impedem a infiltração, causando efeitos catastróficos devido ao aumento do escoamento superficial e a redução na recarga da água 
subterrânea. Na figura 1 observa-se a irregularidade do escoamento, visto que à medida que a precipitação aumenta, ele se intensifica consideravelmente ou reduz-se drasticamente quando essa diminui.

Figura 1 - Representação da geometria do escoamento

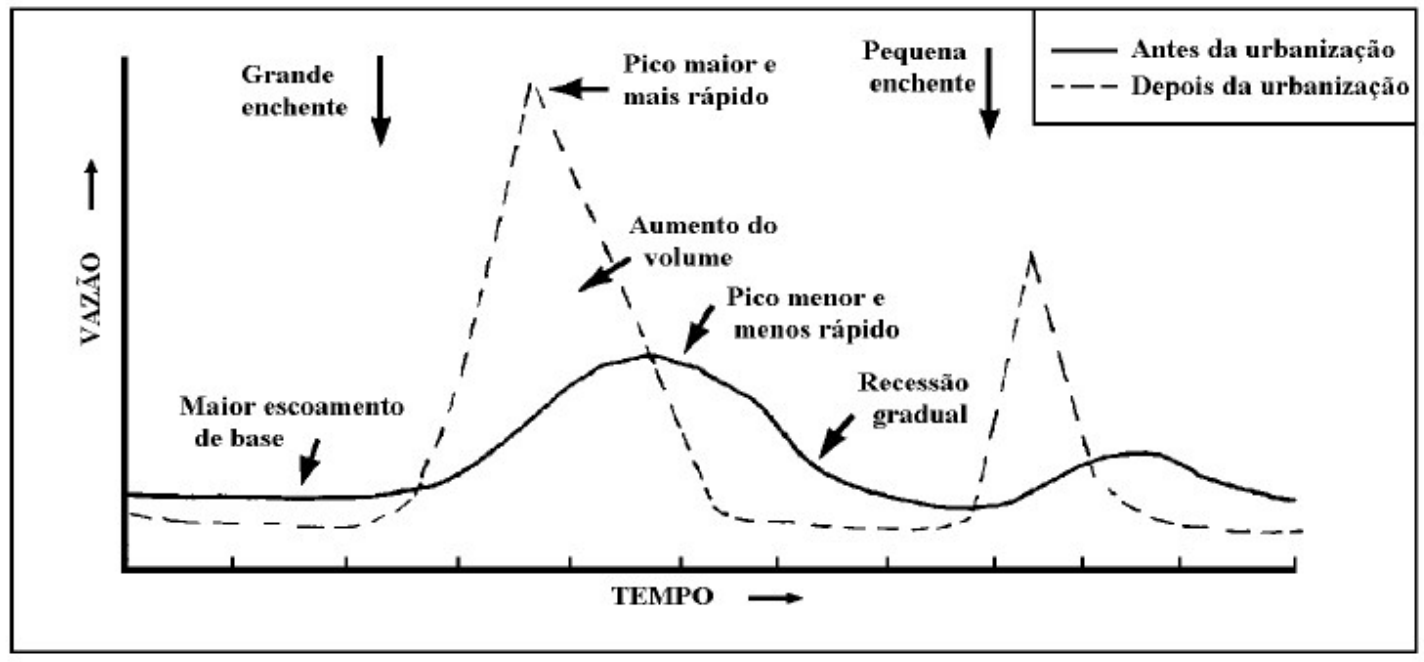

Fonte: TUCCI, 1997.

\subsubsection{Consequências da impermeabilização}

A impermeabilização está diretamente ligada à urbanização e está presente em vias pavimentadas, estacionamentos e telhados. Ela consiste na perda da capacidade de infiltração da água pluvial no solo e da evapotranspiração. Tal situação pode ocasionar a obsolescência sucessiva e incontrolável das redes de drenagem comumente usadas, levando a inundações cada vez mais frequentes em áreas urbanizadas, o que causa grandes consequências sociais, ambientais, políticas e econômicas (PINTO, 2011). Dentre os diversos impactos causados estão o escoamento superficial gerado pela diminuição da permeabilidade do solo devido às construções sem planejamento; as inundações causadas pelo escoamento superficial ocasionando diversos transtornos à sociedade, como prejuízos patrimoniais e econômicos, além de perdas de vidas; e a deterioração da qualidade da água e assoreamento dos rios ocasionados pelo transporte pluvial de sedimentos.

Devido à impermeabilização do solo, o escoamento ocorre, principalmente, pelos condutos e canais, diminuindo a infiltração e aumentando o volume que escoa pela 
superfície. Como a capacidade de defluência nas sarjetas, nos condutos e nos canais é superior à das superfícies naturais e dos riachos, o escoamento superficial chega mais rápido ao rio principal, provocando vazões maiores do que as naturais. (TUCCI e GENZ, 1995)

\subsection{As consequências do uso dos pavimentos convencionais e a utilização de novas técnicas}

A impermeabilização dos solos após a urbanização desordenada agravou os problemas relativos às inundações nas cidades, isso levou à necessidade de novas técnicas de drenagem urbana. A tendência moderna nessa área é a utilização de mecanismos que aumentem o percentual de infiltração da água e que reduzam o escoamento superficial.

Um tipo de dispositivo utilizado para esse fim é o pavimento permeável; ele é capaz de diminuir o volume de escoamento e vazões de pico, além de reduzir o impacto da qualidade da água e dos sedimentos (ARAÚJO et al., 2000). O pavimento permeável, segundo Urbonas e Stahre (1993) citados por Araújo et al. (2000), é uma alternativa de dispositivo de infiltração onde o escoamento superficial é desviado através de uma superfície permeável para dentro de um reservatório de pedras localizado sob o pavimento. Esse tipo de pavimento é constituído por duas camadas de agregados (uma de agregado fino ou médio e outra de agregado graúdo) mais a camada do pavimento propriamente dito (SCHUELLER, 1987).

A construção da camada superior dos pavimentos permeáveis e convencionais é similar. Nos pavimentos porosos parte da areia fina da mistura dos agregados é retirada, assim eles possuem um maior volume de vazios que os usuais, proporcionando maior índice de infiltração. Segundo Araújo et al (2000), o escoamento infiltra rapidamente no revestimento poroso (5 a $10 \mathrm{~cm}$ ), passa por um filtro de agregado com diâmetro de 1,25 $\mathrm{cm}$ e espessura de $2,5 \mathrm{~cm}$ aproximadamente, seguindo para um reservatório de pedras com agregados entre 3,8 a 7,6 cm de diâmetro. Após isso, a água escoada se infiltra no subsolo ou pode ser coletada por tubos de drenagem.

Os pavimentos permeáveis possuem certas vantagens em relação aos demais sistemas de drenagem. Segundo Epa (1999) citada por Acioli (2005), são elas: tratamento da água da chuva por meio da remoção de poluentes, diminuição da necessidade de meiofio e canais de drenagem, aumento da segurança da rodovia com a diminuição de 
derrapagens e ruídos, recarga do aquífero, dispositivo de drenagem integrante à obra, não necessitando de espaço exclusivo.

Como desvantagens, podem ser citadas: a pouca perícia dos engenheiros e contratantes com relação à tecnologia, a tendência de o pavimento poroso se tornar obstruído se inapropriadamente instalado ou mantido, uma alta taxa de falhas no pavimento poroso, o risco de contaminação do aquífero, dependendo das condições do solo e da suscetibilidade do aquífero. (EPA, 1999)

De acordo com Schueler (1987), os pavimentos permeáveis têm altas taxas de falhas, sendo que as principais são: perda parcial ou total da capacidade de infiltração, deformação da camada de pavimento, insuficiência na absorção do solo, dentre outras. Então, para um bom funcionamento, o pavimento poroso precisa de manutenção. Essa manutenção deve incluir sucção a vácuo dos poros, pelo menos quatro vezes ao ano, com eliminação apropriada do material removido, seguida de injeção de água com mangueira de alta pressão, de forma a manter os poros abertos e limpos (ACIOLI et al, 2003).

\subsection{Pavimentação em concreto}

O concreto é formado pela mistura de Cimento Portland, água, aditivos, agregado graúdo e pouco ou nenhum agregado miúdo. A distribuição granulométrica e a qualidade destes componentes interferem no grau de porosidade do concreto, o que influencia diretamente na permeabilidade.

De acordo com Monteiro (2010), a ausência de agregados miúdos caracteriza o concreto poroso (figura 2) resultando em uma estrutura permeável. Ele é utilizado, principalmente, para pavimentação como técnica compensatória de amortecimento de cheias, com o intuito de diminuir o escoamento das águas pluviais.

De acordo com Marchioni (2011) citado por Nabeshima et al. (2011), “estes pavimentos reduzem o escoamento superficial em até 100\%, dependendo da intensidade da chuva, e retardam a chegada da água ao subleito reduzindo a erosão". Os materiais utilizados na estrutura desses pavimentos devem possuir granulometria específica, que permita o escoamento da água infiltrada para o solo ou para um sistema de drenagem.

Uma das principais diferenças entre o concreto convencional e o concreto poroso é a resistência ocasionada pelo índice de vazios. Para que a pasta de cimento não escorra para o fundo, o concreto deve ser pouco adensável, e as vibrações aplicadas em períodos 
curtos, pois, caso contrário, a pasta se tornaria homogênea e com capacidade insuficiente de absorção de água. $\mathrm{O}$ concreto poroso ilustrado na figura 2, é indicado para locais onde há uma menor solicitação de cargas, como ciclovias, quadras poliesportivas, estacionamentos e calçadas.

Figura 2 - Concreto poroso

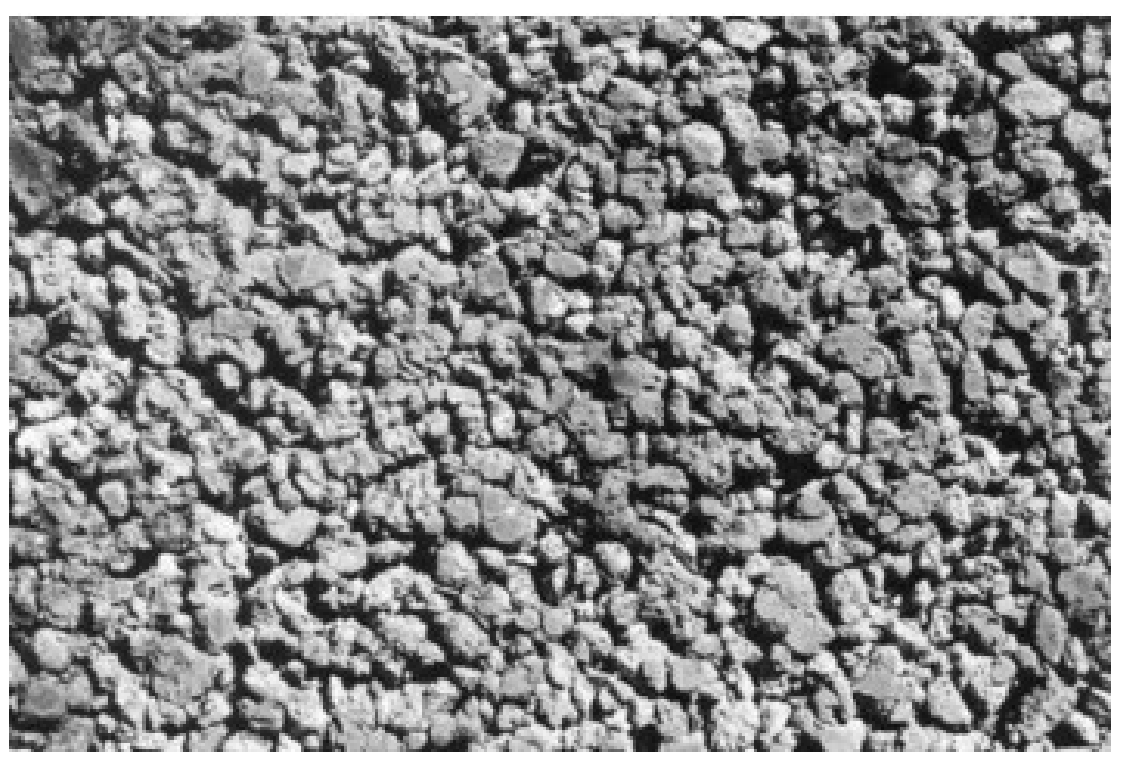

Fonte: Monteiro, 2010.

\subsubsection{Pavimentos de blocos de concreto}

Os blocos de concreto são também conhecidos como Pavers e Paviess. Dentre os blocos de concreto, os mais utilizados na pavimentação são os maciços, vazados e os permeáveis, e o que os difere é a capacidade de penetração de água no solo. Apresentam bom desempenho em qualquer condição climática, entretanto podem movimentar-se ou desalinhar-se quando submetidos a tráfego frequente de automóveis segundo Urbonas e Stahre (1993) citados por Pinto (2011).

Usualmente esses pavimentos são constituídos por duas camadas: a camada de rolamento e a base. A base tem como função impedir que os blocos migrem para o solo natural (subleito), acima dela situa-se a camada de assentamento e os blocos de concreto. Ainda com relação a esse tipo de pavimento, não é usual a utilização de sarjetas, visto que ele possui uma permeabilidade considerável.

\subsubsection{Pavimentos de blocos de concreto intertravados}


Conforme citado anteriormente, os pavimentos de concreto são constituídos por camadas. A permeabilidade dos blocos de concreto (figura 3) depende da permeabilidade do material utilizado, da granulometria do material de assentamento e do espaçamento entre um bloco e outro. Conforme Wiebbelling (2015), as espessuras das camadas do pavimento intertravado dependem da intensidade do tráfego que circulará sobre o pavimento, das características do terreno de fundação e da qualidade dos materiais.

Figura 3 - Blocos intertravados

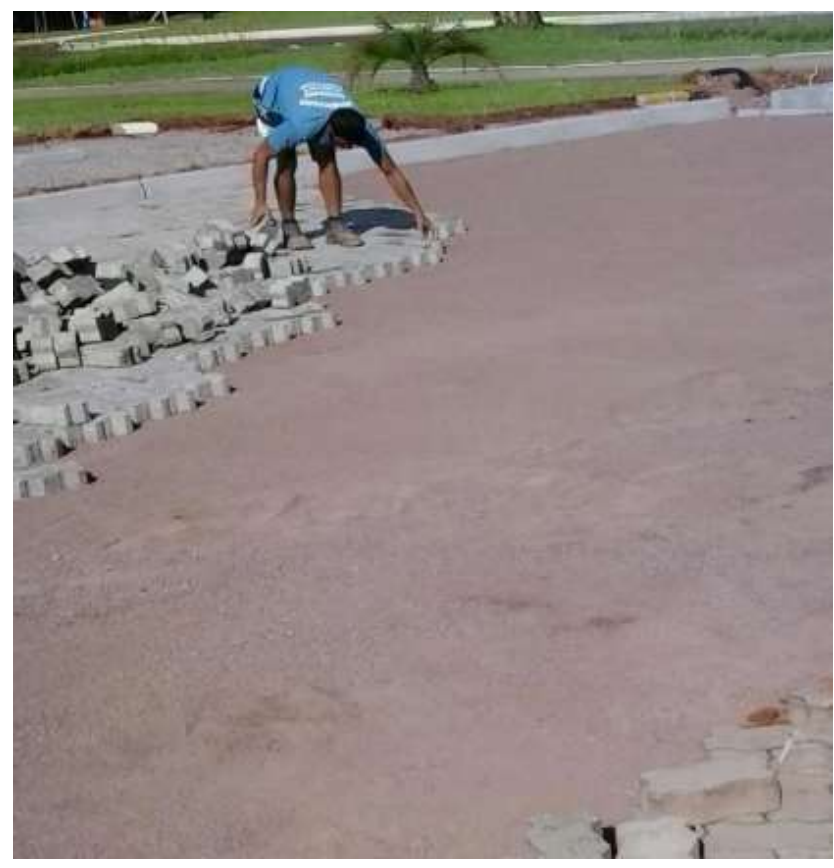

Fonte: Wiebbelling, 2015.

De acordo com Fioriti (2007) citado por Wiebbelling (2015), o intertravamento é a capacidade que o material tem de resistir aos movimentos de deslocamento individual, seja vertical, horizontal, de rotação ou giração em relação às peças adjacentes. 
Figura 4 - Estrutura do pavimento com blocos intertravados de concreto

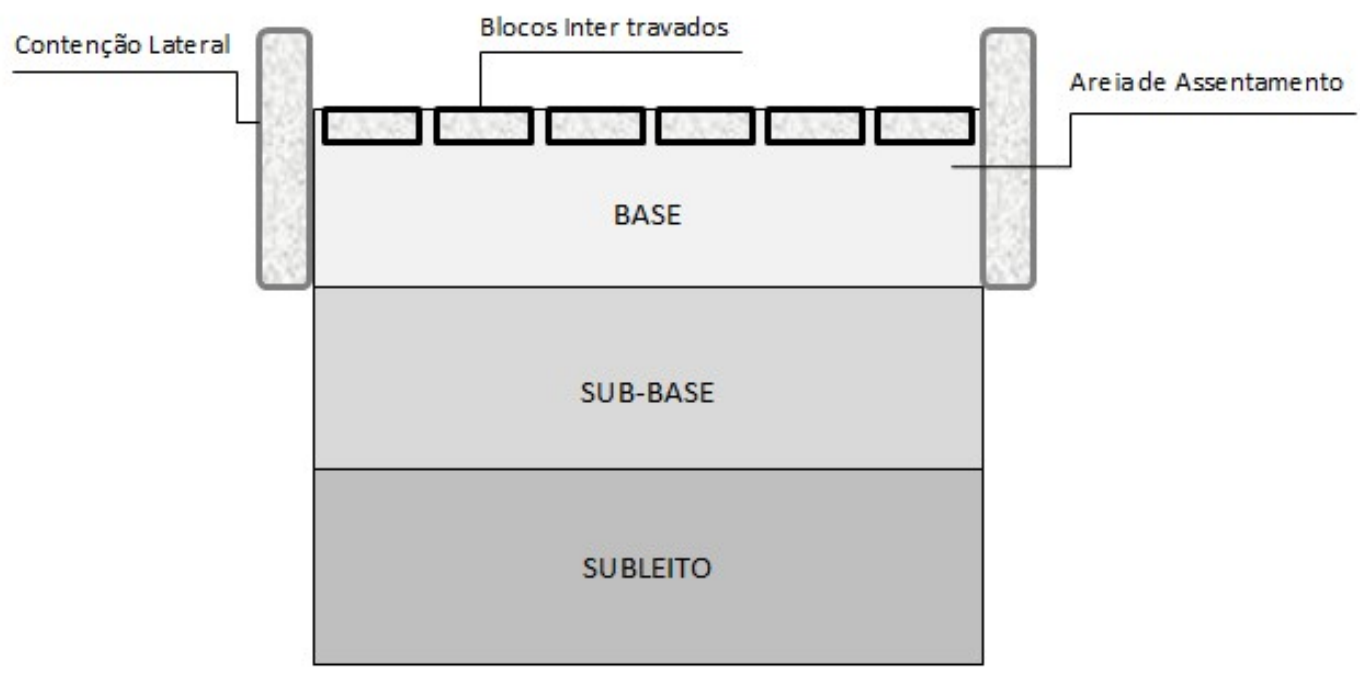

Fonte: Elaboração própria.

\subsubsection{Vantagens e desvantagens da utilização dos blocos de concreto intertravados}

As vantagens dos blocos de concreto, conforme Junior (2007) citado por Wiebbelling (2015), são: eles apresentam menor absorção da luz solar, evitando o desconforto da elevação exagerada da temperatura ambiente; podem ter, simultaneamente, capacidade estrutural e valor paisagístico; permitem fácil reparação quando ocorrer recalque no subleito que comprometa a capacidade estrutural do pavimento; possibilitam fácil acesso a serviços subterrâneos e o reparo não deixa marcas visíveis; os blocos podem ser reutilizados; não requerem mão-de-obra especializada para sua instalação; os materiais chegam até a obra prontos para a aplicação; liberação rápida do tráfego logo após a conclusão; alta taxa de permeabilidade, principalmente, nas juntas; e facilidade de assentamento.

Segundo Nabeshima et al. (2011), uma das maneiras de elevar a taxa de permeabilidade do pavimento em questão é com o aumento da espessura das juntas, por meio da utilização de espaçadores, permitindo maior infiltração da água pela areia de rejuntamento. Desde que bem preenchidas, juntas com maior espessura não interferem na resistência dos blocos e nem no intertravamento existente entre eles. Por outro lado, tornam crescente o efeito da trepidação dos veículos. 
Ainda segundo Nabeshima et al. (2011), pode-se citar como desvantagens a baixa resistência mecânica, o carreamento de finos para a superfície, o desgaste dos veículos que trafegam sobre os locais com este tipo de pavimento, o deslocamento das peças, a despadronização com relação à qualidade das peças encontradas no mercado, a dificuldade de manutenção, o custo elevado e o elevado tempo de execução.

\subsubsection{Pavimentos de blocos de concreto vazado}

Os blocos de concreto vazado permitem a permeabilização de áreas urbanas através da cavidade existente no centro de cada bloco, geralmente é feita a utilização de grama para preenchimento desta cavidade, o que permite maior infiltração da precipitação no solo. Suas características são basicamente as mesmas dos blocos de concreto intertravados.

Segundo UDFCD (2002) citado por Acioli (2005), os blocos vazados de concreto possuem aberturas (furos) em sua estrutura que permitem que a água penetre o reservatório. Os blocos são assentados da mesma forma que os intertravados convencionais maciços. As aberturas podem ser preenchidas com areia, cascalho ou tufos de grama. No caso do preenchimento com grama, as raízes das mesmas devem ficar abaixo da superfície do bloco, para evitar o esmagamento pelos pneus dos carros. Os blocos devem possuir pelo menos $20 \%$ de sua área superficial em vazios.

\subsection{Asfalto CBUQ}

O Concreto Betuminoso Usinado a Quente (CBUQ), também designado como Concreto Asfáltico Usinado a Quente (CAUQ), pode ser considerado a mais comum e tradicional mistura asfáltica a quente empregada no país, e é utilizado na construção dos revestimentos de pavimentos, incluindo as capas de rolamento e as camadas de ligação (BALBO, 2007). A estrutura do CBUQ é composta por múltiplas camadas, sendo a principal delas a camada de revestimento, que é responsável pelo recebimento e transmissão das cargas dos veículos e pela proteção contra as intempéries.

O CAUQ é um revestimento flexível, como mostra a figura 5, e consiste na mistura de agregados e Betume corretamente dosados. O revestimento com o concreto betuminoso consiste em uma mistura de pedra britada, areia e cimento asfáltico de 
Petróleo (Betume), gerando um conjunto estável de máxima densidade. Essa mistura é feita em usinas fixas a quente, que aquecem os agregados e o produto betuminoso. $\mathrm{O}$ material resultante dessa mistura é, então, carregado quente em caminhões que o transportam para a obra, tomando-se o cuidado especial para que a mistura não esfrie durante o transporte pois o espalhamento e a compactação devem ser feitos a quente. (NOGUEIRA, 1961)

Ainda segundo Nogueira (1961), ao finalizar a pavimentação, a fim de fechar os poros do concreto betuminoso, recomenda-se a aplicação de uma capa selante com Betume $1,51 / \mathrm{m}^{2}$ e a pulverização imediata de pedrisco fino (pó de pedra) $101 / \mathrm{m}^{2}$, seguidos da compressão com o rolo tandem.

Figura 5 - Pavimento flexível (corte transversal)

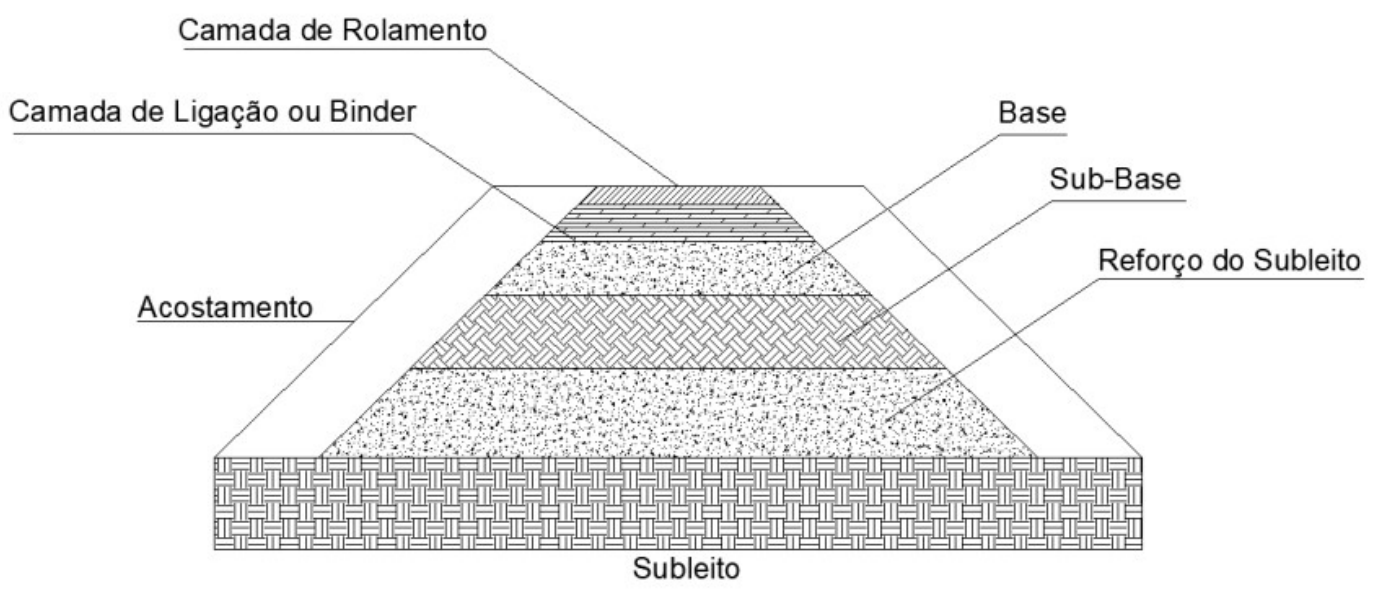

Fonte: Elaboração própria.

O CBUQ se sobressai aos demais revestimentos e tem como principais características a aplicação rápida e com menor sujeira; a liberação do tráfego imediata, pois não exige tempo de cura; ser impermeabilizante; ter envelhecimento lento; manter menor desagregação. Todavia, por ser uma mistura impermeabilizante, esse tipo de pavimento acarreta aquaplanagem e inundações, gerando diversos problemas à população.

\subsection{Asfalto com maior índice de permeabilidade}


A granulometria do agregado é uma das características que asseguram estabilidade aos pavimentos, em consequência do maior atrito interno obtido por entrosamento das partículas, desde a mais graúda à partícula mais fina (DENIT, 2006).

As misturas asfálticas com granulometrias abertas do tipo CPA possuem uma grande porcentagem de vazios com ar não preenchidos, devido a pequenas quantidades de filler, de agregado miúdo e de ligante asfáltico, em que $18 \%$ a $25 \%$ dos vazios são ar.

$\mathrm{Na}$ França essas misturas asfálticas podem conter até 30\% de vazios com ar. A CPA tem sua vantagem quando em contato com o pavimento em dias de chuva, visto que o contato entre pneu e pavimento é maior. Até que a água alcance as sarjetas, esse revestimento é responsável pela captação de águas pluviais para o seu interior e é capaz de promover uma rápida infiltração devido à sua elevada permeabilidade.

A característica importante dessa mistura asfáltica é que ela causa uma diminuição considerável da espessura da lâmina d'água na superfície do pavimento e, consequentemente, das distâncias de frenagem. Outro ponto positivo é a redução da água borrifada pelos pneus dos veículos, aumentando assim a distância de visibilidade e a redução da reflexão da luz dos faróis noturnos. Todos esses aspectos agindo sistematicamente são responsáveis pela redução do número de acidentes em dias de chuva. Além disso, causa a redução de ruído ao rolamento, amenizando esse desconforto ambiental em áreas próximas de vias com revestimentos drenantes. Essa camada drenante é executada sobre uma camada de mistura densa e estrutural.

A figura 6 mostra uma foto de uma rodovia com um revestimento convencional do tipo CA denso, seguido de um trecho com CPA em um dia chuvoso. Observa-se a diferença da presença de água na superfície do CA e a reflexão de luz dos faróis, o que não acontece quando se analisa o trecho consecutivo com CPA.

Já a figura 7 exibe a CPA executada no Aeroporto Santos Dumont no Rio de Janeiro em 2003, onde houve ensaios de permeabilidade e aspectos da textura superficial logo após a construção. A especificação brasileira do DNER-ES 386/99 define que para CPA devem existir cinco faixas granulométricas e teor de ligante asfáltico entre 4,0 e $6,0 \%$. Porém, devido à peculiaridade granulométrica, a quantidade de ligante é geralmente reduzida. 
Figura 6 - Trecho de CA seguido por trecho CPA

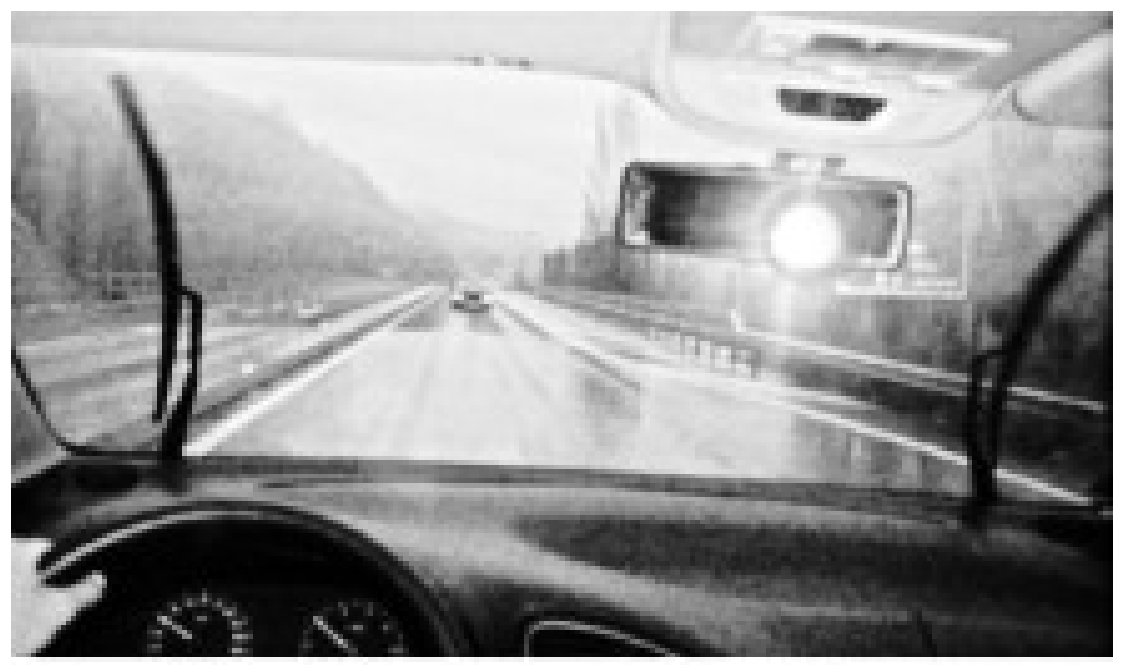

Fonte: Bernucci et al., 2008.

Figura 7 - Trecho de CPA Aeroporto Santos Dumont no Rio de Janeiro

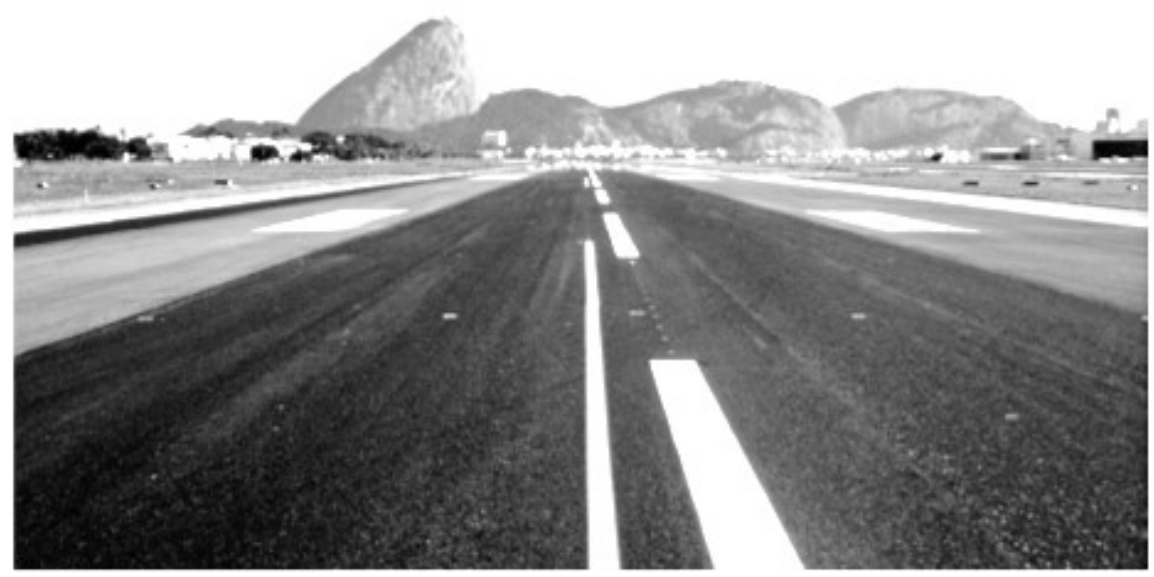

Fonte: Bernucci et al., 2008.

O ligante asfáltico deve ter baixa suscetibilidade térmica e alta resistência ao envelhecimento. É recomendada a utilização de asfalto modificado por polímero para aumentar a durabilidade e reduzir a desagregação. A camada inferior à CPA deve ser necessariamente impermeável para que não entre água no interior da estrutura do pavimento. A CPA deve ser dosada pelo método Marshall, prevalecendo o volume de vazios requerido. Os agregados devem ser $100 \%$ britados e bem resistentes para não serem quebrados na compactação, pois eles estão em contato uns com os outros e a tensão nesse contato é muito elevada durante o processo de densificação. 
Para se ter um contato bom entre os agregados, eles devem ser cúbicos com o índice de forma $\geq 0,5$. A absorção de água para cada fração deve ser no máximo de $2 \%$, e quanto à sanidade deve apresentar perda de $\leq 12 \%$. Para se testar o pavimento, recomenda-se a realização do teste de desgaste por abrasão Cântabro, no qual os espanhóis foram pioneiros para esse tipo de mistura aberta drenante. Para diminuir os problemas de colmatação, ou seja, a elevação desse pavimento, que são consequências da contaminação dos vazios por impurezas, uma vez que devido a elas há redução da permeabilidade, deve-se efetuar a limpeza deles. Na Europa tem-se aplicado a limpeza desses revestimentos após certo tempo de uso com equipamentos projetados para essa finalidade.

Como exemplos da utilização da camada porosa de atrito no Brasil, são citadas as seguintes obras:

Aeroporto Santos Dumont no Rio de Janeiro: em 1999, foi executado um pavimento superposto, na pista principal, e sobre ele aplicada uma CPA nos $923 \mathrm{~m}$ centrais. Para manter esse nível de atrito, a camada de CPA foi renovada em 2003, nos pontos de maior uso, visto que houve colmatação dos vazios e perda de capacidade drenante ao final de seis anos de uso intenso.

$\mathrm{Na}$ Rodovia dos Imigrantes que liga São Paulo a Santos, também foi aplicado esse dispositivo, sendo que em 1998 foi feita uma restauração através de fresagem seguida de recapeamento com uma espessura de $5 \mathrm{~cm}$ entre os quilômetros 11,5 e 30 .

Outro local em que foi adotado o CPA foi a Rodovia Presidente Dutra, próxima à São Paulo. Em 1998, 3km nas três faixas e no acostamento apresentavam condições precárias antes da restauração. Foi efetuada uma fresagem do revestimento existente ou recomposição do greide da pista com caimento de $3 \%$, foi executada uma camada de $2 \mathrm{~cm}$ de microrrevestimento asfáltico a frio e aplicada o CPA com $4 \mathrm{~cm}$ de espessura.

\section{CONSIDERAÇÕES FINAIS}

A urbanização desenvolveu-se de maneira rápida e concentrada nas médias e grandes cidades. Os usos e ocupações do solo se deram dentro da bacia hidrográfica, de forma periférica aos cursos hídricos e, na maioria das vezes, de forma indevida, acarretando inundações nos períodos chuvosos. 
As inundações urbanas ocorrem devido às mudanças nos recursos hídricos, à ampliação de áreas impermeáveis e sua consequente diminuição da infiltração de água no solo, ou seja, do aumento do escoamento superficial que fomenta as vazões dos cursos hídricos e aumenta o prejuízo das pessoas de áreas adjacentes.

Os principais fatores do processo de inundações urbanas, em essência, ocorrem pela falta de um olhar sistêmico para os elementos que compõe a natureza e fenômenos climatológicos e hidrológicos e da falta de investimento em tecnologias que contribuam para os projetos de drenagem. Acrescenta-se também a falta de instrumentos de gestão, política e planejamento que visem medidas de controle da drenagem pluvial urbana, o disciplinamento dos usos e ocupações dos solos instituídos pelos órgãos municipais e do controle dos resíduos sólidos urbanos.

Diante dos problemas supracitados, viu-se a necessidade da implantação de novos mecanismos que amenizassem o escoamento superficial. Assim, devem ser adotados pavimentos permeáveis que são facilitadores da infiltração da água no subsolo. $O$ pavimento permeável pode ser utilizado em diversos lugares para diminuir a erosão, inundações, o assoreamento de rios e para beneficiar a manutenção do nível do lençol freático. Além disso, pode ser uma solução para problemas enfrentados por lugares que sofrem com inundações em áreas urbanas.

Porém, mesmo oferecendo inúmeros benefícios ao meio urbano, poucas cidades aderem a esse dispositivo, visto que necessitam de manutenção esporádica e apresentam maior custo de incorporação comparado ao convencional. 


\section{REFERÊNCIAS}

ACIOLI, Laura Albuquerque et al. Implantação de um módulo experimental para a análise da eficiência de pavimentos permeáveis no controle de escoamento superficial na fonte. In: Simpósio Brasileiro de Recursos Hídricos, Curitiba, 2003.

ACIOLI, Laura Albuquerque. Estudo experimental de pavimentos permeáveis para o controle do escoamento superficial na fonte. Dissertação (Programa de Pós-Graduação em Recursos Hídricos e Saneamento Ambiental) - Universidade Federal do Rio Grande do Sul Porto Alegre, 145 p., 2005.

ALESSI, Fernando et al. Comparação do escoamento superficial gerado por pavimentos permeáveis em blocos de concreto e asfalto permeável. Da

Vinci. Curitiba, v.3, n. 1, p. 139-156, 2006.

ARAÚJO, Paulo Roberto de. et al. Avaliação da eficiência dos pavimentos permeáveis na redução do escoamento superficial. Revista Brasileira de Recursos Hídricos. v. 5, n. 3, p. 21-29, jul. 2000.

BALBO, Tadeu José. Pavimentação asfáltica: materiais projeto e restauração. Oficina de Textos, 560 p., 2007.

MONTEIRO, Anna Carolina Neves. Concreto poroso: dosagem e desempenho. Trabalho de Conclusão de Curso (Graduação em Engenharia Civil) - Universidade Federal de Goiás, 36 p., 2010.

NABESHIMA, Cinthia Kaori Yabe. Análise comparativa entre sistemas de pavimentação urbana baseados em concreto asfáltico e blocos de concreto intertravados (Pavers). Dissertação (Graduação em Engenharia de Produção Civil) Universidade Tecnológica Federal do Paraná. 123 f., Curitiba, 2011.

NOGUEIRA, Cyro. Pavimentação: projeto e construção. Rio de Janeiro: Ao Livro Técnico, 1961.

PINTO, Liliane Lopes Costa Alves. O desempenho de pavimentos permeáveis como medida mitigadora da impermeabilização do solo urbano. Tese (Doutorado em Engenharia Hidráulica) - Escola Politécnica da Universidade de São Paulo, São Paulo, $2011,255 \mathrm{f}$.

SCHUELER, Thomas R. Controlling urban runoff: a pratical manual for planning and designs BMP's. Washington, 1987.

TEIXEIRA, Wilson et al. Decifrando a terra. 2 ed. São Paulo: Oficina de Texto, 558 p., 2003.

TUCCI, Carlos E. M. Água no meio urbano. Instituto de Pesquisas Hidráulicas, Universidade Federal do Rio Grande do Sul, 40 p., 1997. 
TUCCI, Carlos E.M., GENZ, Fernando. Controle do impacto da urbanização. In: TUCCI, Carlos E.M., PORTO, Rubem L.L., BARROS, Mário T. de. (Org.) Drenagem urbana. Porto Alegre: Editora da Universidade UFRGS: ABRH. cap. 7, p. 277-348, 1995.

URBONAS, Ben.; STAHRE, Peter. Stormwater: best management pratices and detention for water quality. Englewood Cliffs: Prentice Hall. New Jersey, 450 p., 1993.

WIEBBELling, Paula Orvana Guimarães. Pavimento com blocos intertravados de concreto: Estudo de caso na Univates. Lajeado, 2015. 